\title{
Pollinators and visitors of the generalized food-deceptive orchid Dactylorhiza majalis in North-Eastern Poland
}

\author{
Beata Ostrowiecka ${ }^{1}$ (1) - Izabela Tałałaj ${ }^{1} \cdot$ Emilia Brzosko $^{1} \cdot$ Edyta Jermakowicz $^{1} \cdot$ Paweł Mirski $^{1}$ • \\ Agata Kostro-Ambroziak ${ }^{1} \cdot$ Łukasz Mielczarek $^{2}$ - Andrzej Lasoń $^{3}$ • Janusz Kupryjanowicz ${ }^{4}$ - Jarosław Kotowicz ${ }^{5}$. \\ Ada Wróblewska ${ }^{1}$
}

Received: 18 December 2018 / Accepted: 13 May 2019 / Published online: 24 May 2019

(C) The Author(s) 2019

\begin{abstract}
Pollinator foraging behavior plays a key role in breeding and therefore affects the evolution of the orchid reproductive strategy. Food-deceptive orchids usually implement a generalized plant pollination strategy and a relatively diverse group of pollinators visit them. Dactylorhiza majalis is a food-deceptive, early-flowering orchid that relies on insect-mediated pollination. This study's objectives were to identify $D$. majalis' pollinators and flower visitors and their foraging behaviors on $D$. majalis inflorescences. We also assessed the bending movement time to determine the relationship between bending time and the duration of pollinators' visits. To assess pollination efficiency, we measured the spur length of D. majalis flowers, which is expected to affect the mechanical fit to pollinators/"potential" pollinators. The arthropod fauna were investigated to examine the availability of "potential" pollinators in populations. We identified Apis mellifera as this orchid's main pollinator and confirmed that few of the flower visitors belonged to Diptera (12 individuals, 9 taxa), Hymenoptera ( 3 individuals, 3 taxa), or Coleoptera (2 individuals, 2 taxa) in our dataset, which was collected over a 2 -year period and includes $360 \mathrm{~h}$ of video. The arthropods were collected by a sweep net in D. majalis populations and there were fewer Hymenoptera (2.9-23.2\%) and Coleoptera (4.4-23.8\%) visitors but more Diptera (23.3-58.6\%) visitors. We found that A. mellifera foraged in different ways on D. majalis inflorescences, thereby resulting in cross-pollination and/or geitonogamy; however, the bending time data supported the hypothesis about promoting cross-pollination while decreasing self-pollination, but these data do not exclude the possibility of geitonogamy.
\end{abstract}

Keywords Apis mellifera $\cdot$ Pollinators $\cdot$ Flower visitors $\cdot$ Non-rewarding orchids $\cdot$ Plant-pollinator interaction

Electronic supplementary material The online version of this article (https://doi.org/10.2478/s11756-019-00285-0) contains supplementary material, which is available to authorized users.

Beata Ostrowiecka

b.ostrowiecka@uwb.edu.pl

1 Faculty of Biology and Chemistry, Institute of Biology, University of Bialystok, K. Ciołkowskiego 1J, 15-245 Białystok, Poland

2 University of Agriculture in Krakow, Al. Mickiewicza 21, 31-120 Krakow, Poland

3 Białystok, Poland

4 The Andrzej Myrcha University Centre of Nature, University of Bialystok, K. Ciołkowskiego 1J, 15-245 Białystok, Poland

5 Faculty of Mathematics and Informatics, University of Bialystok, K. Ciołkowskiego 1M, 15-245 Białystok, Poland

\section{Introduction}

Different pollination strategies have evolved in flowering plants. The great diversity of these strategies is demonstrated in Orchidaceae (Jersáková et al. 2009; Willmer 2011): generalized food deception and sexual deception are the most common mechanisms of pollination (Cozzolino and Widmer 2005; Jersáková et al. 2006). Unlike sexually-deceptive orchids, food-deceptive orchids usually implement a generalized pollination strategy and are visited by a relatively diverse group of pollinators, i.e., mostly bees, but also (rarely) butterflies and beetles (Cozzolino and Widmer 2005). Pollinator behavior undoubtedly plays a key role in the evolution of food-deceptive flowers (Jersáková et al. 2006). Generalized food-deceptive orchids advertise general floral signals that are typical for rewarding species (Jersáková et al. 2006) and start flowering significantly earlier than rewarding orchids (Kindlmann and Jersáková 2006; Pellissier et al. 2010). To 
receive visits from pollinators, deceptive orchids presumably take advantage of the sensory and behavioral biases of pollinators; for example, flower color and scent can attract pollinators from a distance. Pollinators usually gather around abundant food resources and might occasionally also visit non-rewarding plants in the vicinity. In this case, a flower might be discovered via the instinctive foraging behaviors of a nectar-seeking insect and the flower thus avoids the physiological costs of producing nectar and the potential reproductive costs of geitonogamous pollination. Additionally, geitonogamous pollination can be reduced by the bending movement of pollinarium that occurs in most European orchids (Johnson and Edwards 2000; Claessens and Kleynen 2011). Bending time is associated with the length of time spent by the pollinator on a plant (Peter and Johnson 2006). Pollinators spend less time on inflorescences without rewards than on rewarding ones; consequently, bending times must be short to prevent self-pollination between flowers in nonrewarding than rewarding plants.

Early-flowering, food-deceptive orchids can be pollinated by naïve insects, which results in increasingly frequent visits (Internicola et al. 2007). In this case, early flowering evolves to exploit the higher average density of inexperienced pollinators and lower competition between deceptive orchids and co-flowering, rewarding plants (Internicola et al. 2008). In accordance with this, Tremblay et al. (2005) identified that individuals that flower early have higher pollination rates than those that flower later. The advantages of early flowering have been demonstrated in Cypripedium japonicum, where visitations by bumblebee workers occurred primarily when this orchid first began to bloom (Sun et al. 2009). Bees learn positive stimuli faster than negative stimuli (non-rewarding visits) (Menzel and Greggers 1992) and can learn after a single trial (Menzel 1993). Experienced bumblebees that have learned the colors of rewarding species make fewer mistakes when choosing between two plant species with dissimilar colors (Internicola et al. 2007). The contrast in the visitation frequency and reproductive success of early-flowering, deceptive orchids often depends on the density of other rewarding species, annual variation in the emergence of bees, and location of the orchid population (Johnson et al. 2003; Renner 2005; Jersáková et al. 2009). However, the assumptions that rewardless orchid species always rely on naïve pollinators and that pollination success decrease over the season cannot be validated without further research (Waser and Ollerton 2006).

Claessens and Kleynen (2011) reported that Dactylorhiza taxa are food-deceptive orchids pollinated by a diverse group of insects. Pollinators of Dactylorhiza taxon are frequently members of the orders Hymenoptera, Lepidoptera, and Coleoptera across the geographic range (Claessens and Kleynen 2011). Dactylorhiza majalis is an early-flowering orchid. The taxonomic identification of $D$. majalis pollinators is still scarce in the literature, especially those pollinators from the northern parts of the European range. So far, seven species of Hymenoptera (Bombus pascuorum, B. pratorum, B. lucorum, B. rurerarius, B. soroeensis, B. terrestris, and $B$. sicheli) and one species of Coleoptera (Actenicerus sjaelandicus) (Claessens and Kleynen 2011 and literature cited therein) have been reported as pollinators of D. majalis. Hansen and Olesen (1999) identified bumblebees as the most abundant pollinators of D. majalis in Denmark. In Germany, Knuth (1899) reported that only representatives of the Hymenoptera visited D. majalis flowers (Apis mellifera, Bombus agrorum, $B$. confusus, $B$. distinguendus, $B$. hortorum, B. lapidarius, B. muscorum, B. terrestris, Eucera longicornis, Halictus leucozonius, Nomada sexfasciata, and Osmia fusca). Additionally, Ruiz (2010) identified Apis mellifera as a D. majalis pollinator in Spain. All these observations focused on the taxonomic identification of the pollinators, whereas their foraging behaviors on D. majalis inflorescences were not described. Therefore, the main goals of our study were the taxonomic identification of $D$. majalis pollinators and floral visitors and to collect observations of their foraging behavior on D. majalis inflorescences in three different populations in north-eastern Poland via videotaping. We also investigated the lengths of the floral spurs, which are expected to affect the mechanical fit for pollinators/"potential" pollinators and thereby pollination efficiency (Nilsson 1988; Sletvold and Ågren 2011), and the bending time of the caudicles, which can prevent geitonogamy in orchids. To assess the arthropod richness in these habitats and to identify "potential" pollinators (insects with $D$. majalis pollinaria), we investigated the arthropod fauna in three populations during the flowering of this orchid.

\section{Materials and methods}

\section{Study species}

Dactylorhiza majalis (Rchb.) P.F. Hunt \& Summerh. is assumed to be an allotetraploid terrestrial, self-compatible, long-lived, and tuberous perennial orchid that reproduces by seeds or (rarely) vegetatively (Vakhrameeva et al. 2008). It produces a single inflorescence with $\sim 20-35$ violet-purple flowers with short, violet, and nectarless spurs (Vakhrameeva et al. 2008). The stigma is placed above the spur entrance. The labellum is large and covered by visual guides ("honey guides") that lead to the spur (Hansen and Olesen 1999; Claessens and Kleynen 2013). D. majalis' pollinaria can be removed as one or two units during a single pollinator visit. Caudicles are very elastic and can stretch up to ten times their length; Claessens and Kleynen (2011 according to Darwin 1877) reported the estimated time for pollinaria bending on the insect body as $30 \mathrm{~s}$. D. majalis blooms from 
May to June and fruits occur from June to July; the fruit set varied from $16.2 \%$ to $77.5 \%$ (Claessens and Kleynen 2011). D. majalis is widely distributed across Europe and grows in moist, waterlogged meadows and fens with slightly acidic to strongly alkaline $\mathrm{pH}$ values (5.2-8.1) (Procházka and Velísek 1983; Hulten and Fries 1986; Vakhrameeva et al. 2008; Claessens and Kleynen 2011; Balao et al. 2016).

\section{Study sites}

Three populations of $D$. majalis (SKI, SKII, and KA, Table 1) were examined from May-June of 2014-2017 (each site was visited for two consecutive years). All these sites were located in north-east Poland (in the vicinity of Białowieża Primeval Forest) at the northern geographic distribution range of D. majalis (Hulten and Fries 1986). D. majalis grows in wet meadows with abundant, entomophilous plants (which cover $\sim 20 \%$ of the herb layer in all populations, Table 1). The study sites differed in the abundance of $D$. majalis individuals, from 200 and 300 individuals in SKI and SKII, respectively, to $\sim 1000$ individuals in KA (Table 1). All the meadows were extensively used, mown every year in late July or early August, and not artificially fertilized.

\section{Reproductive success relative to floral display}

Bending times of orchid pollinaria were recorded by withdrawing them from the anthers on the toothpick and measuring their movement until they were in horizontal position. The pollinaria bending time was measured from four inflorescences with a total of 16 pollinaria in KA (2015), nine inflorescences with 20 pollinaria in SKI (2015), and 19 inflorescences with 31 pollinaria in SKII (2016).

To test the effect of the length of spur on the female and male success and fruit set, plants were randomly labelled (using plastic tags) in each population in a given year (a total of 119 and 104 plants in 2014 and 2015, respectively in KA; 93 and 70 plants in 2015 and 2016, respectively in SKI; 70 and 80 plants in 2016 and 2017, respectively in SKII). The number of flowers per inflorescence was counted and all flowers within inflorescence were divided into three levels according to their position within an inflorescence (i.e. the lower, middle and upper parts). The division of flowers on inflorescence was made for each plant according to the rule, so that the upper and lower levels contain the same number of flowers and no more than one third of all flowers. The middle level had at most two flowers more than the upper and lower levels. During the flowering period the length of a random

Table 1 The characteristic of three Dactylorhiza majalis populations in north-eastern Poland

\begin{tabular}{|c|c|c|c|c|c|c|}
\hline Population & Code & $\begin{array}{l}\text { Population } \\
\text { size } \\
\text { (individuals) }\end{array}$ & Coordinates & $\begin{array}{l}\text { Fruit } \\
\text { set }\end{array}$ & $\begin{array}{l}\text { (year); mean spur length in } \\
\text { lower, middle, upper } \\
\text { flower in mm }( \pm \mathrm{SD}) \text {, } \\
\text { Friedman test }\end{array}$ & $\begin{array}{l}\text { Type of community, co-flowering rewarding plant species } \\
\text { (their covering in herb layer) }\end{array}$ \\
\hline Kapitańszczyzna & $\mathrm{KA}$ & $\sim 1000$ & $\begin{array}{l}52^{\circ} 53^{\prime} 01^{\prime \prime} \\
\mathrm{N} \\
23^{\circ} 40^{\prime} 30^{\prime \prime} \\
\mathrm{E}\end{array}$ & $12.4 \%$ & $\begin{array}{l}(2014) ; 11.1( \pm 1.4), 10.3 \\
( \pm 1.6), 9.0( \pm 2.1) \\
\chi^{2}=40.39, \mathrm{df}=2, \\
p=0.000 \\
(2015) ; 9.1( \pm 2.2), 9.5( \pm \\
1.5), 7.2( \pm 1.4), \\
\chi^{2}=96.45, \mathrm{df}=2, \\
p=0.000\end{array}$ & $\begin{array}{l}\text { Open, wet meadow with Ranunculus acris, Myosotis } \\
\text { palustris, Lychnis flos-cuculi, Trifolium pratense, } \\
\text { Cardamine pratensis }(20 \%)\end{array}$ \\
\hline Skupowo I & SKI & $\sim 200$ & $\begin{array}{l}52^{\circ} 50^{\prime} 04^{\prime \prime} \mathrm{N} \\
23^{\circ} 41^{\prime} 46^{\prime \prime} \mathrm{E}\end{array}$ & $\begin{array}{l}35.9 \% \\
50.1 \%\end{array}$ & $\begin{array}{l}(2015) ; 7.9( \pm 1.6), 6.9( \pm \\
1.7), 5.3( \pm 1.9), \\
\chi^{2}=91.29, \mathrm{df}=2, \\
\mathrm{p}=0.000 \\
(2016) ; 8.6( \pm 1.4), 7.0( \pm \\
1.3), 5.7( \pm 1.3), \\
\chi^{2}=97.51, \mathrm{df}=2, \\
\mathrm{p}=0.000\end{array}$ & $\begin{array}{l}\text { Open, wet meadow with Ranunculus acris, Geum rivale, } \\
\text { Veronica chamaedrys, Alchemilla vulgaris, Polygonum } \\
\text { bistorta }(20 \%)\end{array}$ \\
\hline Skupowo II & SKII & $\sim 300$ & $23^{\circ} 42^{\prime} 53^{\prime \prime} \mathrm{E}$ & $\begin{array}{l}50.6 \% \\
43.3 \%\end{array}$ & $\begin{array}{l}(2016) ; 8.1( \pm 1.6), 8.1( \pm \\
1.7), 7.5( \pm 1.9), \\
\chi^{2}=32.36, d f=2, \\
p=0.000 \\
(2017) ; 6.9( \pm 1.4), 6.8( \pm \\
1.3), 6.5( \pm 1.3), \\
\chi^{2}=25.75, d f=2, \\
p=0.000\end{array}$ & $\begin{array}{l}\text { Open, wet meadow with Ranunculus acris, Geum rivale, } \\
\text { Veronica chamaedrys, Alchemilla vulgaris, Polygala } \\
\text { vulgaris, Cardamine pratensis, Trifolium pretense, } \\
\text { Lathyrus pratensis (20\%) }\end{array}$ \\
\hline
\end{tabular}

The differences in spur length between the lower, middle, and upper flowers in a given year was estimated using a Friedman test 
spur at each level of inflorescence was measured for each plant (a total of 357 and 312 flowers in 2014 and 2015, respectively in KA; 279 and 210 flowers in 2015 and 2016, respectively in SKI; 210 and 240 flowers in 2016 and 2017, respectively in SKII). A Friedman non-parametric ANOVA test was used to show the differences in spur lengths between the lower, middle, and upper positions on the inflorescences in each population in consecutive years. At the end of the flowering period the number of taken pollinia by insects (i.e. male reproductive success) and female success (fruits) from each flower within inflorescence of plant, and position of flowers were recorded. For each plant and each level fraction of fruits was calculated as ratio between the fruits produced on this level and the number of available flowers on the level. The Kruskal-Wallis test was used to show differences between levels of fruit set on the stem in each year of observation. Similarly average number of taken pollinia per flower for each plant and each level was calculated as ratio between the number of taken pollinia from flowers on this level and the number of available flowers on the level. In order to determine the correlation between the fraction of fruits, the average number of collected pollinia and the length of spurs in a given population and at a given level, Spearman's rank correlation coefficients with their significance levels were calculated. All statistical analysis were conducted in R Core Team (2018).

\section{Arthropod sampling}

Arthropods were collected using a sweep net (Yi et al. 2012) during the three flowering stages of $D$. majalis in each year: at the beginning (almost all flowers were in buds, and only a single opened flower can be seen on each of the inflorescences; KA - 9.05.2014, 25.05.2015; SKI - 21.05.2015, 16.05.2016; SKII - 23.05.2016, 17.05.2017), during the optimum (almost all the flowers on the inflorescences were opened; KA - 19.05.2014, 2.06.2015; SK1-25.05.2015, 21.05.2016; SKII - 23.05.2016, 29.05.2017), and at the end of flowering (perianths have begun to dry out; KA 10.06.2014, 12.06.2015; SKI - 12.06.2015, 30.05.2016; SKII - 3.06.2016, 9.06.2016), about 1.5 h between 9:00 am and 3:00 pm. Arthropods were sampled along three linear, parallel transects per site $(100 \mathrm{~m} \times 1 \mathrm{~m}$ each). Five samples per transect were taken by 20 swings in a $180^{\circ}$ arc at a length of $20 \mathrm{~m}$. The arthropods collected by sweeping were transferred into plastic bottles, taken to the laboratory, and frozen. Arthropods were stored in Eppendorf tubes with 70\% ethyl alcohol. Next, we taxonomically categorized the caught arthropods into one of four groups (Hymenoptera, Diptera, Coleoptera, or other arthropods) and estimated their frequency in the separated taxonomic groups at each $D$. majalis flowering stage, in each population, and for consecutive years. We also compared the frequency of open, fresh flowers changing in the following days with the frequency of arthropods from different taxonomic groups at each flowering stage (beginning, optimum, and end of flowering) in each population and for each year. The pollinators from collected arthropods were noted; $D$. majalis was the only orchid flowering at this time in the vicinity of the Bialowieża Primeval Forest, and therefore, when arthropods bore $D$. majalis pollinaria, we easily identified them as pollinators.

\section{Pollinators and flower visitor observations}

To record the flower visitors of $D$. majalis, two flowering individuals whose flowers contained pollinaria in each population were videotaped using digital video cameras (HDRCX410VE, Sony Corp., Japan or HDRPJ780VE, Sony Corp., Japan) during five sunny, warm, and windless days between 9:00 am and 3:00 pm, during the peak in the flowering period ( $\sim 90 \%$ of the flowers were opened). The number of open flowers was counted for each individual plant. Inflorescences were recorded between 19 and 26 May in 2014 and 28 May and 3 June in 2015 for the KA population; between 25 May and 2 June in 2015 and 27 May and 1 June in 2016 for the SKI population; and between 23 and 30 May in 2016 and 24 May and 1 June in 2017 for the SKII population. In total, within populations, $60 \mathrm{~h}$ of observation were conducted. For recordings, we set the cameras on tripods that were about $1-1.5 \mathrm{~m}$ away from the plants. The recordings were analyzed and the insects were identified and categorized into different functional groups. We identified flower visitors as insects that landed on the flowers but did not carry D. majalis pollinaria. Insects were considered to be pollinators (pollen vector) when they carried the pollinaria of $D$. majalis. We noted the number of arthropods and recorded the behavior of the pollinators and visitors on D. majalis. We also calculated the mean visitation frequencies as the number of visits per flower per time unit $(\mathrm{V})$. The mean number of flowers visited per inflorescence per single bout was recorded $\left(\mathrm{N}_{\mathrm{f}}\right)$ and the flower visitation rate $\left(V_{f}\right)$ for each of the specimens was recorded as the mean number of visited flowers per second.

\section{Results}

\section{Reproductive success relative to floral display}

The reproductive success measured by female success ranged between $12.4 \%$ (KA, 2015) to 50.6\% (SKII, 2017, Table 2) and usually was slightly higher at the lower level than at the middle level of stem, and statistically significant in relation to the upper level of stem (Supplementary Table 1). Female success was positively and significant correlated with male success at all three levels on stem (i.e. the lower, middle and upper parts) within each year in SKI population (from $r^{2}=$ $0.320, p<0.05$ to $\left.r^{2}=0.638 p<0.001\right)$ and in SKII at the 


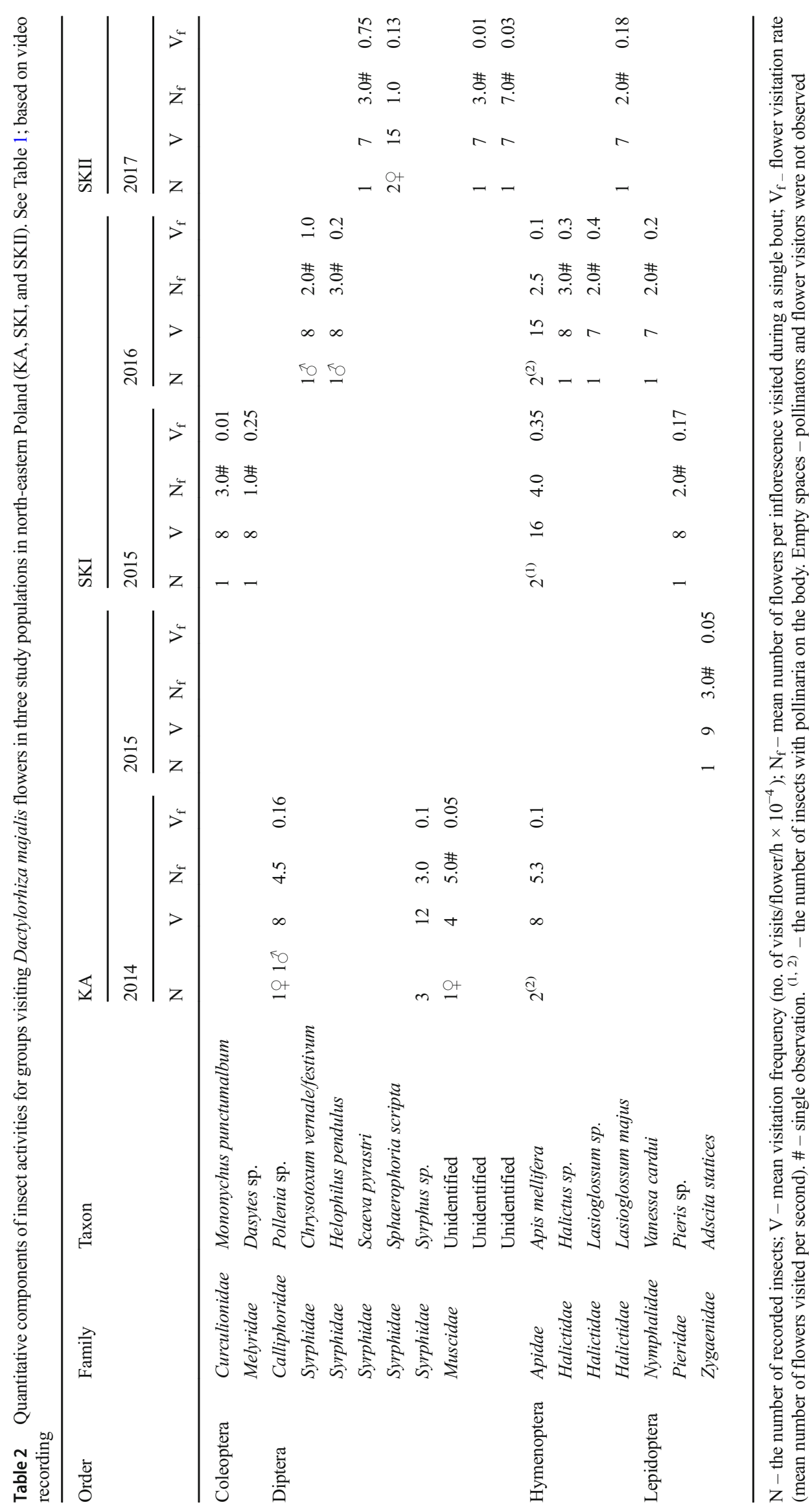


second $\left(r^{2}=0.567, p<0.001\right.$ in 2016) and the third level (from $r^{2}=0.287, p<0.05$ to $0.460, p<0.001$, respectively, 2017 and 2016; Supplementary Fig. 1). In KA population this correlations was significant only in 2015 year at third level $\left(r^{2}=0.249-0.262, p>0.05\right.$; Supplementary Fig. 1$)$. The positive and significant correlations between length of spur and fruit set were noted in SKII at the third level of stem in 2016 year $\left(r^{2}=0.316, p>0.05\right)$ with mean length of spur $7.5 \pm 1.7$ as well as in SKI at the second level of stem both in 2015 and 2016 year $\left(r^{2}=0.346\right.$ and $r^{2}=0.281, p>0.05$, respectively), when the mean length of spur at this level were $6.9 \pm 1.7$ and $7.0 \pm 1.3$, respectively. We observed no significant relationships between length of spur and number of taken pollinaria within populations and at almost three levels. Flower position affected the spur length in the D. majalis populations in all years (Table 1). The upper flowers had relatively shorter spurs $(5.3 \mathrm{~mm} \pm 1.9-9.0 \mathrm{~mm} \pm 2.1)$ than the middle $(6.8 \mathrm{~mm} \pm 1.3-10.3 \mathrm{~mm} \pm 1.6)$ and lower $(6.9 \mathrm{~mm} \pm 1.4$ $11.1 \mathrm{~mm} \pm 1.4$ ) flowers in all three populations and each year.

The time before the pollinarium had undergone its full angle of movement varied between $20 \mathrm{~s}$ and 2 min $5 \mathrm{~s}$ (mean = $54 \mathrm{~s} \pm 55)$ in KA, between $8 \mathrm{~s}$ and $1 \mathrm{~min} 12 \mathrm{~s}($ mean $=39 \mathrm{~s} \pm$ 18) in SKI, and between $20 \mathrm{~s}$ and $1 \mathrm{~min} 20 \mathrm{~s}($ mean $=49 \mathrm{~s} \pm 9$ ) in SKII ( $\mathrm{H}=0.47, p>0.05$, Kruskal-Wallis test). The bending speed and direction differed, and therefore, the margin of error might be a few seconds.

\section{Arthropod assemblages in populations}

A total of 13,694 individual arthropods were collected from the three populations during 2 years of observations. We observed 4098 arthropods (accounting for $\sim 30 \%$ of the dataset) that belonged to 11 orders in the KA population, 4856 (accounting for $\sim 35 \%$ of the dataset) belonged to 17 arthropod orders in SKI, and 4740 (also $35 \%$ of the dataset) belonged to 12 arthropod orders in SKII. In total, the highest frequency of arthropod individuals collected from all populations was from the order Diptera, constituting 30.5-36.8\% (2014 and 2015 , respectively) of the total KA population, $29.2-32.5 \%$ (2015 and 2016, respectively) of the SKI population, and 40.2-51.3\% (2016 and 2017, respectively) of the SKII population. Coleoptera and Hymenoptera were the next-most numerous groups, but their frequencies did not exceed $20 \%$ in the analyzed years. The least abundant arthropod group, in all the populations, was Lepidoptera. Other single arthropods were recognized as one group due to the lack of reports in the literature about them as visitors or pollinators of D. majalis (Hemiptera, Thysanoptera, Orthoptera, Plecoptera, Odonata, Megaloptera, Neuroptera, Collembola, Myriapoda, and Arachnida).

In a comparison of the arthropod frequency with the frequency of open, fresh flowers changing in the following days, we did not observe any overlap between these two variables.
In each year within a given population, the frequencies of the following arthropod groups reached relatively similar abundances. The most abundant order of arthropods within the three flowering stages was Diptera (ranging from $23.3 \%$ to $58.6 \%$ in the populations (Fig. 1)), followed by Coleoptera (4.4\% and $23.8 \%$ ) and Hymenoptera (2.9\% to $23.2 \%$ (Fig. 1)). The arthropods collected using the sweep net did not carry pollinaria.

\section{Pollinators and flower visitors}

Only Apis mellifera individuals were categorized as pollinators of D. majalis (Fig. 2). Among six individual honey bees, five carried pollinaria. The mean visitation frequency $(V)$ for A. mellifera pollinators was extremely low and was observed in the KA and SKI populations; it varied from $8.1 \times 10^{-4}$ visits/flower/h in KA to $16.4 \times 10^{-4}$ visits/flower/h in SKI. During a single bout per inflorescence $\left(\mathrm{N}_{\mathrm{f}}\right.$, Table 2$)$, A. mellifera visited an average of three flowers in SKI and five flowers in KA. Visits of A. mellifera on inflorescences lasted 33-40 s in KA, $13 \mathrm{~s}$ in SKI, and 11-37 s in SKII.

We recorded seven insects visiting the flowers of D. majalis in KA, and these insects belonged to four taxa and four families. In SKI, eight insects visited the flowers and belonged to eight taxa and six families, and in SKII, six insects visited the flowers and belonged to five taxa and three families (Table 2). In the KA and SKII populations, most visits were done by Diptera (66.7\% and $83.3 \%$, respectively) species, whereas in the SKI population, visits were done by different insects at a similar frequency (25\%). One lepidopteran was recorded in the KA population and two were recorded in the SKI population. We recorded no flower visitors in the SKII population throughout 2016 (Table 2).

For visitors, the mean visitation frequency varied from $4 \times$ $10^{-4}$ to $12 \times 10^{-4}$ in KA, $8 \times 10^{-4}$ to $16 \times 10^{-4}$ in SKI, and $7 \times$ $10^{-4}$ to $15 \times 10^{-4}$ in SKII. Dasytes sp. and Sphaerophoria scripta visited the fewest flowers during a single bout in SKI and SKII, respectively, and Diptera visited the most flowers in SKII. The flower visitation rate $\left(\mathrm{V}_{\mathrm{f}}\right)$ was the lowest in SKI for Mononychus punctumalbum $(0.01 \mathrm{~s})$ and the highest in SKII for Scaeva pyrastri (0.75 s) (Table 2).

\section{Discussion}

\section{Apis mellifera as the $D$. majalis pollinator}

Our video observations showed that honey bees (Apis mellifera) are the main $D$. majalis pollinator, consistent with an older survey from Germany (Knuth 1899) and another more recent one from Spain (Ruiz 2010). A. mellifera is a cultivated species in vast areas of Central Europe and the availability of $A$. mellifera pollinators in the 

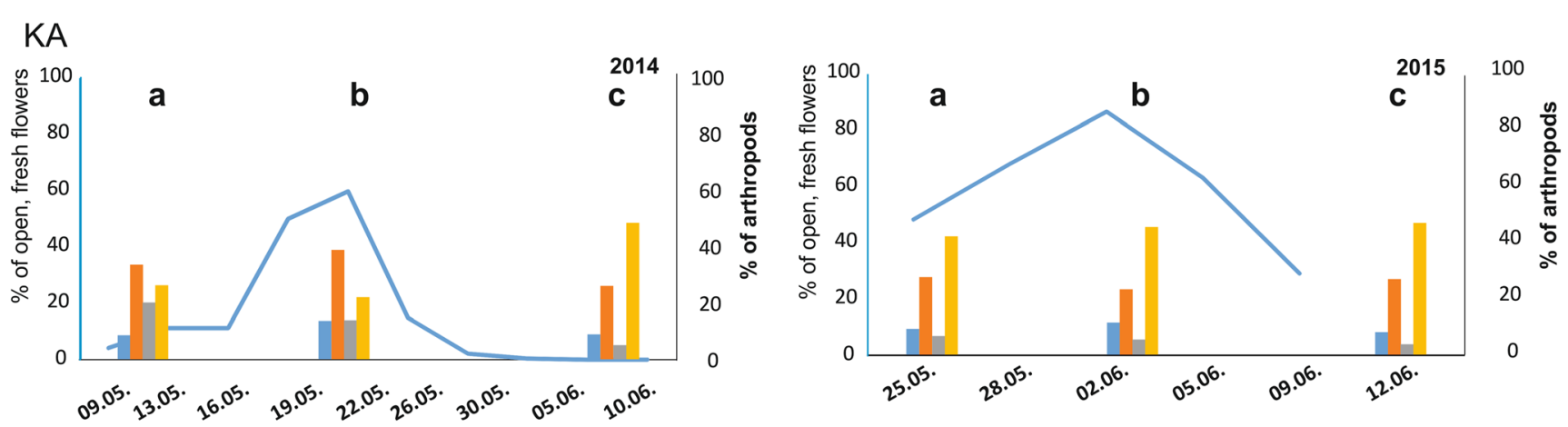

\section{SKI}
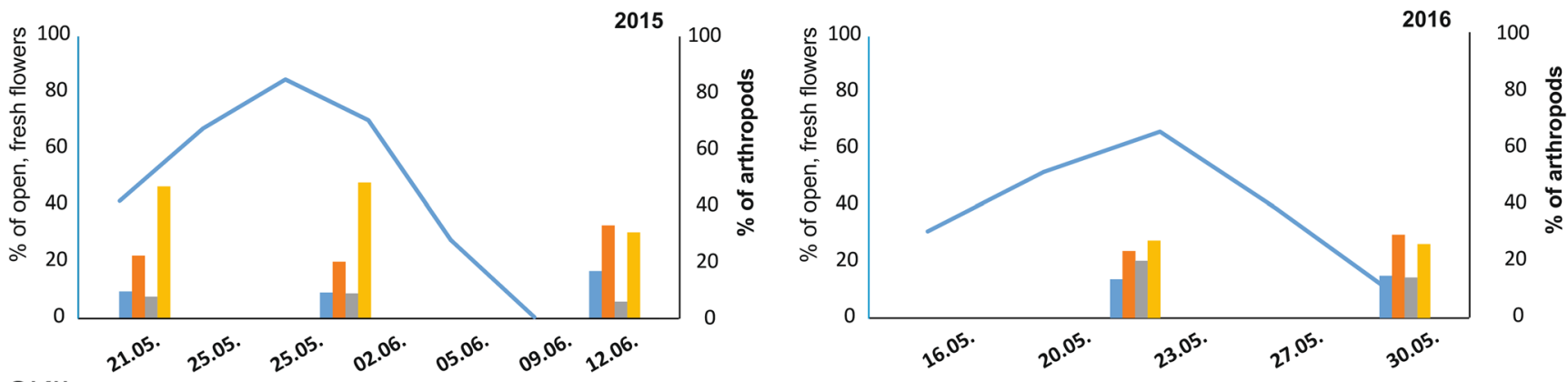

SKII
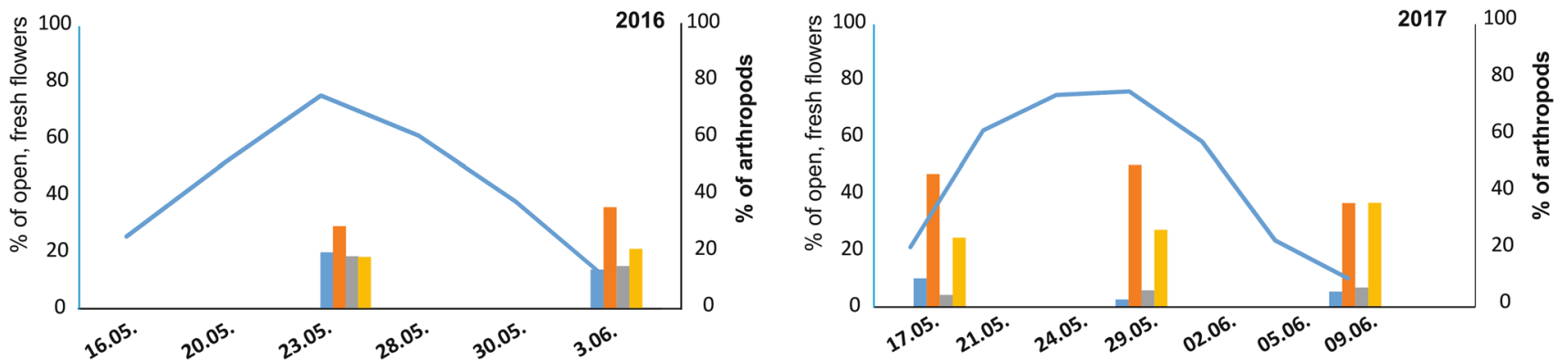

\section{Hymenoptera}

Diptera

Coleoptera

other arthropods

Fig. 1 The abundance of different taxonomic groups of arthropods collected at the three flowering stages: a, beginning; b, optimum; c, end of flowering (see "Materials and methods" section) of D. majalis individuals in the KA, SKI, and SKII populations during 2014-2017 in north-eastern Poland

Kapitańszczyzna and Skupowo areas might be a consequence of the many apiaries in close proximity to $D$. majalis populations. Biró et al. (2015) showed that A. mellifera is a significant pollinator promoting higher reproductive success in the deceptive Himantoglossum adriaticum (Orchidaceae) population near the honey bee apiary. We did not consider A. mellifera as a "native" pollinator in an evolutionary sense, but rather a widely introduced, super-generalist species that occupies a central role in many pollination networks (Medan et al. 2006; Russo 2016). On the other hand, we did not ignore Bombus as the "native" D. majalis pollinator, even though we did not videotape them but only observed Bombus in sweep nets (Ostrowiecka, personal data). The Bombus species was confirmed as important pollinators for both $D$. majalis (Müller 1881; Knuth 1899; Hansen and Olesen 1999; Berger 2005;
Paulus 2005; Claessens and Kleynen 2011) and other Dactylorhiza taxa (Godfery 1933; Vöth 1993, 1999; Cozzolino et al. 2005; Kropf and Renner 2005) in different parts of their geographical ranges.

It is surprising that, despite the numerous apiaries surrounding the studied populations, we recorded an extremely low visitation frequency of $A$. mellifera to the $D$. majalis inflorescences. The low visitation frequency of $A$. mellifera and lack of Bombus species in our video records might result from the fact that these insects quickly learn to avoid deceptive flowers (avoidance learning; Internicola and Harder 2012). A similar phenomenon was described by Catling and Kostiuk (2011), where a lack of visits of Bombus on Galearis rotundifolia inflorescences was noted, despite the finding that they were frequent on adjacent plants. However, 


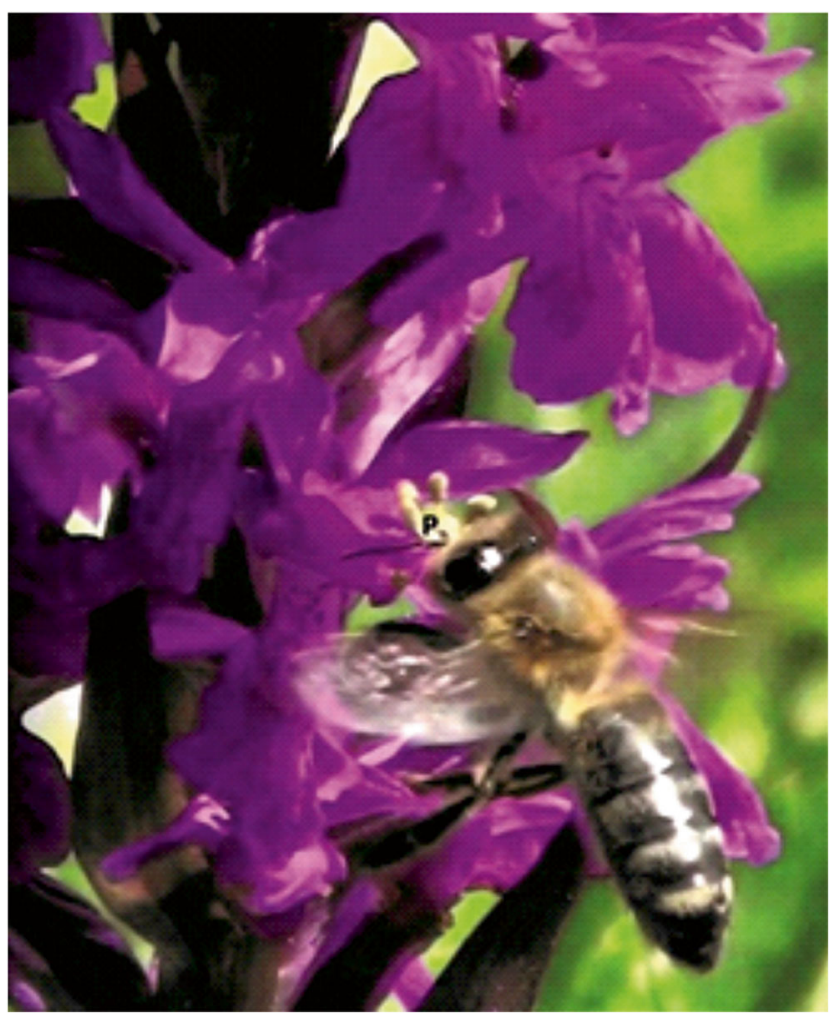

Fig. 2 Apis mellifera as a pollinator of Dactylorhiza majalis with transported pollinaria $(\mathrm{P})$; population SKI (photo, Beata Ostrowiecka)

we propose that the low visitation frequency of pollinators should be interpreted with caution because the natural fruit set ranged from $12.4 \%$ to $50.6 \%$ in $2014-2017$ in the three studied D. majalis populations. Our observation confirmed also the fact that in almost all populations and at different levels of inflorescence the pollinaria were removed and number of removed pollinaria was positively significant correlated with number of fruit set, which suggests higher effective pollination rates by A. mellifera and/or by other insects, e.g., Bombus. Many authors studied orchid pollinators highlighted the fact that it is difficult to directly observe orchid pollination events, especially in orchids with deceptive pollination systems (Neiland and Wilcock 1998, Johnson et al. 2003). Additionally, Nilsson (1984) pointed out sequences of bumblebee visits to deceptive Anacamptis morio flowers on only eight occasions during 10 years of observations on Öland Island. In other surveys, despite observing the fruit set, the pollinators have never been observed (Pérez-Hérnandez et al. 2011) or noted occasionally at frequencies that do not reflect the level of reproductive success (Moré et al. 2012; Steen and Mundal 2013; Sexton 2014; Esposito et al. 2017).

The reason why A. mellifera and potentially other insects can be lured by $D$. majalis is the floral chemical compounds released by $D$. majalis, which were reported by Wróblewska et al. (2019) in populations from north-eastern Poland. These chemical compounds include p-hydroxybenzyl alcohol (a volatile compound in Vanilla, describing it as vanilla-like), and aldehydes (which are important components of floral odor in the appetitive proboscis extension response in honey bees, Wang et al. 2016), particularly nonanal. Another important factor in orchid-insect interactions is how the morphological fit between flowers and pollinators affects pollen deposition. According to Cariveau et al. (2016), A. mellifera belongs to the long-tongued hymenopterans with proboscis lengths of $\sim 6-7 \mathrm{~mm}$ described in populations in Europe, Asia, and North America (Atwal and Sharma 1968; Ruttner 1988; Ibrahim et al. 2017). Such a long proboscis can reach the base of the spur of $D$. majalis and - in the same moment - the viscidium can adhere to the insect's head. The D. majalis spur is a medium-length spur, according to the phylogenetic classification in the Dactylorhiza genus (Adcock et al. 1983; De Hert et al. 2012; Radak et al. 2012; Trunschke et al. 2017; Bateman and Rudall 2018). The fit between the D. majalis spur ca. 6 $7 \mathrm{~mm}$ of length and the mean A. mellifera proboscis length and in consequences their positive significant effect on fruits set in may explain why this insect is a pollinator of this plant (Stang et al. 2006, 2009). The morphology of the D. majalis spur and its floral chemical compounds suggest that this orchid undergoes melittophilous pollination.

While A. mellifera has been recognized as a pollinator of D. majalis, its foraging behavior on D. majalis inflorescences has never been reported. We hypothesized that the behavior of honey bees might lead to both cross-pollination and geitonogamy, leading to mixed mating. We recorded that A. mellifera landed on the inflorescence, entered the flowers, removed pollinaria, and then visited another three to five flowers on the same inflorescence over a period of $11 \mathrm{~s}$ to $40 \mathrm{~s}$. The videotaping also showed that the honey bee landed on the labellum with a single pollinarium and pushed into the flower, thus favoring cross-pollination in the SKI population. Then, the bee removed the pollinaria from the next flower and visited a few neighboring flowers on the same inflorescence (geitonogamy or cross-pollination). We observed that A. mellifera pollinators never repeatedly returned to the same flowers and never visited all the flowers on the inflorescences. On the other hand, the mechanism preventing geitonogamy is pollinaria bending, a time delay before the freshly withdrawn pollinaria can conduct fertilization. In D. majalis populations in north-eastern Poland, the mean delay is $39-54 \mathrm{~s}$, which is considered a relatively long time for deceptive plants and similar to other deceptive Dactylorhiza taxa (Niiniaho 2011). Interestingly, the banding time span in each $D$. majalis population ranged from $8 \mathrm{~s}$ to $2 \mathrm{~min} 5 \mathrm{~s}$. It is likely that this short bending time can provide an opportunity for geitonogamy. This phenomenon and the bending times in the studied populations support our hypothesis that we cannot completely exclude the possibility of geitonogamy in deceptive orchids. Kropf and Renner (2008) pointed out the high levels of geitonogamous pollination in Dactylorhiza 
sambucina and Himantoglossum hircinum and stressed that geitonogamy was not so rare (at least in these orchids, as studied by pollen tracking) as expected by the selfing avoidance hypothesis and that the bending mechanism is not perfect, as can be deduced from the varying bending times reported in literature.

\section{Hymenoptera, Coleoptera, and Diptera as flower visitors}

Among the investigated insects, Hymenoptera and Coleoptera had the lowest overall frequencies, but maintained a similar level of abundance at each of the three $D$. majalis flowering stages. This could be an effect of moderate cultivation (e.g., only one cut per year in the case of meadows and different feeding and arthropod activities during vegetation time). Zahn et al. (2010) observed that the highest abundance of these two taxonomic groups is usually in June and August and rarely in May. Even though hymenopterans and coleopterans were rarely noted in the studied $D$. majalis populations, their representatives - Halictidae, Apidae, and Curculionidae - were exclusively observed as flower visitors in May (via videotaping) and during sweep net collection in the meadows with D. majalis. Banaszak (1989) pointed out that these taxonomic groups are frequently encountered in May and are abundant in meadows, apart from honey bees. The sizes and behavior of the short-tongued hymenopterans Lasioglossum sp. and Halictus sp. and their potential role in the pollination of $D$. majalis with medium-length spurs were revealed by our videotapes. Many authors reported that it is not essential for the spurs to exceed the proboscis length of the pollinators for proper pollination, unlike the many orchids that attach their pollinaria to the head or eyes of the pollinator (Nilsson 1978, 1983, 1988; Nilsson et al. 1987; Robertson and Wyatt 1990). We hypothesized that the $D$. majalis spur length would be adapted to the morphology of short-tongued bees because the spur length varied greatly between the positions on the inflorescence in populations and between years. The spurs in an upper position on the $D$. majalis inflorescence were usually significantly shorter than those in the middle and lower positions, which can influence the likelihood that new potential pollinator groups will emerge. The beetles did not present typical pollinator behavior; they were 'simple visitors' that apparently landed randomly on inflorescences and never actively visited, but rather rested on, the $D$. majalis flowers.

It is worth considering the role of Diptera as pollinators of D. majalis. This group reached the highest numbers of individuals and was more commonly observed in spring during 2014-2017, relative to Hymenoptera and Coleoptera. We noted that $48 \%$ of the visits on D. majalis (from all analyzed populations) were done by dipterans, with the most frequent being hoverflies (Syrphidae, $76.9 \%$ of all flies). Larson et al. (2001) and Ssymank et al. (2008) reported that Diptera is the second-most important pollinator group among insects, particularly Syrphidae, Bombyliidae, and Muscoidea. We never observed flies carrying $D$. majalis pollinaria, although we cannot exclude this as a possibility. A syrphid's proboscis is short, like in Lasioglossum sp. and Halictus sp.; therefore, these flies tend to visit flowers with short tubes and might also be interested in flowers in the upper position on $D$. majalis inflorescences. This phenomenon has been recognized in other orchids (Henneresse and Tyteca 2016).

Co-blooming plant species can share visitors with D. majalis, possibly leading to insects visiting nonrewarding flowers. Lepidopteran species were also observed as visitors but extremely rarely visited the $D$. majalis flowers. They visited two to three flowers on the inflorescence, spending an average of $30 \mathrm{~s}$. During a typical visit, they inserted their proboscis into the spurs to exploit nectar, but they were not able to carry pollinaria. Therefore, we need to take into account the divergence between the $D$. majalis floral features (length of spur) and the morphological structures of insects. Butterflies had tongues longer than the D. majalis spur; they probed flowers without carrying pollinaria. Visits from lepidopteran species on Dactylorhiza were also noted in Ireland, but none carried Dactylorhiza pollinaria (Vallius et al. 2013).

Acknowledgements We thank Damian and Karolina Pogodzińscy for their help in making the field observations. This research was funded by a grant from the National Science Center in Poland (UMO-2013/09/ B/NZ8/03350).

\section{Compliance with ethical standards}

Conflict of interest The authors declare that they have no conflicts of interest.

Open Access This article is distributed under the terms of the Creative Commons Attribution 4.0 International License (http:// creativecommons.org/licenses/by/4.0/), which permits unrestricted use, distribution, and reproduction in any medium, provided you give appropriate credit to the original author(s) and the source, provide a link to the Creative Commons license, and indicate if changes were made.

\section{References}

Adcock EM, Gorton E, Morries GP (1983) A study of some Dactylorhiza populations in greater Manchester. Watsonia 14:377-389

Atwal AS, Sharma OP (1968) Introduction of Apis mellifera queen into Apis indica colonies and the associated behavior of two species. Indian Bee J 30:41-56

Balao F, Tannhäuser M, Lorenzo MT, Hedren M, Paun O (2016) Genetic differentiation and admixture between sibling allopolyploids in the Dactylorhiza majalis complex. Heredity 116:351-361. https://doi. org/10.1038/hdy.2016.119

Banaszak J (1989) Bees (Apoidea) of moist meadows on the Mazovian lowland. Mem Zoologi 43:279-287

Bateman RM, Rudall PJ (2018) Clarified relationship between Dactylorhiza viridis and Dactylorhiza iberica renders obsolete the 
former genus Coeloglossum (Orchidaceae: Orchidinae). Kew Bull 73:4. https://doi.org/10.1007/s12225-017-9728-z

Berger L (2005) Quelques interrogations sur la pollinisation des Dactylorhiza. Bull SFO Rhône-Alpes 12:23-22

Biró É, Bódis J, Nagy T, Tökölyi J, Molnár VA (2015) Honeybee (Apis mellifera) mediated increased reproductive success of a rare deceptive orchid. Appl Ecol Environ Res 13:181-192. https://doi.org/10. 15666/aeer/1301 181192

Cariveau DP, Nayak GK, Bartomeus I, Zientek J, Ascher JS, Gibbs J, Winfree R (2016) The Allometry of bee proboscis length and its uses in ecology. PLoS One 11:e0151482. https://doi.org/10.1371/journal. pone. 0151482

Catling PM, Kostiuk B (2011) Some observation on the pollination of round-leaf orchid, Galearis rotundifolia, near Jasper, Alberta. Can Field Nat 125:47-54. https://doi.org/10.22621/cfn.v125i1.1124

Claessens J, Kleynen J (2011) The flower of the European orchid. Form and function. Jean Claessens and Jacques Kleynen Publishers, Geulle

Claessens J, Kleynen J (2013) The pollination of European orchids. Part 1: introduction and the genera Orchis and Dactylorhiza. J Hardy Orchid Soc 10:83-89

Cozzolino S, Widmer A (2005) Orchid diversity: an evolutionary consequence of deception? Trends Ecol Evol 20:487-494. https://doi.org/ 10.1016/j.tree.2005.06.004

Cozzolino S, Schiestl FP, Müller A, De Castro O, Nardella AM, Widmer A (2005) Evidence for pollinator sharing in Mediterranean nectarmimic orchids: absence of premating barriers? Proc Biol Sci 272: 1271-1278. https://doi.org/10.1098/rspb.2005.3069

Darwin CR (1877) The various contrivances by which orchids are fertilised by insects. John Murray, London, 2d edition

De Hert K, Jacquemyn H, Van Glabeke S, Roldán-Ruiz I, Vandepitte K, Leus L, Honnay O (2012) Reproductive isolation and hybridization in sympatric populations of three Dactylorhiza species (Orchidaceae) with different ploidy levels. Ann Bot 109:709-720. https://doi.org/10.1093/aob/mcr305

Esposito F, Merckx T, Tyteca D (2017) Noctuid moths as potential hybridization agents for Platanthera orchids. Lankesteriana 17:383393. https://doi.org/10.15517/lank.v17i3.31576

Godfery MJ (1933) Monograph and iconograph of native British Orchidaceae. Cambridge University Press, Cambridge

Hansen I, Olesen JM (1999) Comparison of reproductive success in two orchids: the nectarless Dactylorhiza majalis s.s. and the nectar producing Gymnadenia conopsea s.1. Nord J Bot 19:665-671. https://doi.org/10.1111/j.1756-1051.1999.tb00676.x

Henneresse T, Tyteca D (2016) Insect visitors and potential pollinators of Orchis militaris (Orchidaceae) in southern Belgium. J Insect Sci 16: 1-7. https://doi.org/10.1093/jisesa/iew088

Hulten E, Fries M (1986) Atlas of North European vascular plants (North of the Tropic of Cancer), vol 1-3. Koeltz Scientific Books, Königstein

Ibrahim MM, Chandel YS, Anil A (2017) Morphometrics of Apis mellifera after five decades of its introduction in North-Western Himalayan region of India. Pak J Zool 49:1397-1403. https://doi. org/10.17582/journal.pjz/2017.49.4.1397.1403

Internicola AI, Harder LD (2012) Bumble-bee learning selects for both early and long flowering in food-deceptive plants. Proc R Soc 279: 1538-1543. https://doi.org/10.1098/rspb.2011.1849

Internicola AI, Page PA, Bernasconi G, Gigord LDB (2007) Competition for pollinator visitation between deceptive and rewarding artificial inflorescences: an experimental test of the effects of floral colour similarity and spatial mingling. Funct Ecol 21:864-872. https://doi. org/10.1111/j.1365-2435.2007.01303.x

Internicola AI, Bernasconi G, Gigord LDB (2008) Should food-deceptive species flower before or after rewarding species? An experimental test of pollinator visitation behaviour under contrasting phenologies.
J Evol Biol 21:1358-1365. https://doi.org/10.1111/j.1420-9101. 2008.01565.x

Jersáková J, Johnson SD, Kindlmann P (2006) Mechanisms and evolution of deceptive pollination in orchids. Biol Rev 81:219-235. https://doi.org/10.1017/s1464793105006986

Jersáková J, Johnson SD, Jürgens A (2009) Deceptive behavior in plants. II. Food deception by plants: from generalized systems to specialized floral mimicry. In: Baluška F (ed) Plant-environment interactions: from sensory plant biology to active plant behavior. SpringerVerlag, Berlin, pp 223-246

Johnson SD, Edwards TJ (2000) The structure and function of orchid pollinaria. Pl Syst Evol 222:243-269. https://doi.org/10.1007/ BF00984105

Johnson SD, Peter CI, Nilsson LA, Ågren J (2003) Pollination success in a deceptive orchid is enhanced by co-occurring rewarding magnet plants. Ecology 84:2919-2927. https://doi.org/10.1890/02-0471

Kindlmann P, Jersáková J (2006) Effect of floral display on reproductive success in terrestrial orchids. J Folia Geobot 41:47-60. https://doi. org $/ 10.1007 / \mathrm{bf0} 2805261$

Knuth P (1899) Handbuch der Blütenbiologie, unter Zugrundelegung von Herman Müllers Werk: Die Befruchtung der Blumen durch Insekten. Leipzig W. Engelmann, Leipzig

Kropf M, Renner S (2005) Pollination success in monochromic yellow populations of the rewardless orchid Dactylorhiza sambucina. Pl Syst Evol 254:185-197. https://doi.org/10.1007/ s00606-005-0338-0

Kropf M, Renner S (2008) Pollinator-mediated selfing in two deceptive orchids and a review of pollinium tracking studies addressing geitonogamy. Oecologia 155:497-508. https://doi.org/10.1007/ s00442-007-0919-4

Larson BMH, Kevan PG, Inouye DW (2001) Flies and flowers: taxonomic diversity of anthophiles and pollinators. Can Entomol 133: 439-465. https://doi.org/10.4039/ent133439-4

Medan D, Basilio AM, Devoto M, Bartoloni NJ, Torretta JP, Petanidou T (2006) Measuring generalization and connectance in temperate, year-long active systems. In: Waser NM, Ollerton J (eds) PlantPollinator Interactions: from specialization to generalization. The University of Chicago Press, Chicago and London, pp 245-259

Menzel R (1993) Associative learning in honey bees. Apidologie 24:157168. https://doi.org/10.1051/apido:19930301

Menzel R, Greggers U (1992) Biology and evolution of social insects. Leuven University Press, Leuven

Moré M, Amorim FW, Benitez-Vieyra S, Medina AM, Sazima M, Cocucci AA (2012) Armament imbalances: match and mismatch in plant-pollinator traits of highly specialized long-spurred orchids. PLoS One 7:e41878. https://doi.org/10.1371/journal.pone.0041878

Müller H (1881) Alpenblumen, ihre Befruchtung durch Insekten und ihre Anpassungen an dieselben. Wilhelm Engelmann, Leipzig

Neiland MRM, Wilcock CC (1998) Fruit set, nectar reward, and rarity in the Orchidaceae. Amer J Bot 85:1657-1671. https://doi.org/10. $2307 / 2446499$

Niiniaho J (2011) The role of geitonogamy in the reproduction success of a nectarless Dactylorhiza maculata (Orchidaceae). Dissertation, University of Jyväskylä

Nilsson LA (1978) Pollination ecology of Dactylorhiza sambucina (Orchidaceae). Bot Notiser 133:367-385

Nilsson LA (1983) Anthecology of Orchis mascula (Orchidaceae). Nordic J Bot 3:157-179. https://doi.org/10.1111/j.1756-1051.1983.tb01059.x

Nilsson LA (1984) Anthecology of Orchis morio (Orchidaceae) at its outpost in the north. Nova Acta Reg Soc Sci Upsal 5:167-179

Nilsson LA (1988) The evolution of flowers with deep corolla tubes. Nature 334:147-149. https://doi.org/10.1038/334147a0

Nilsson LA, Jonsson L, Ralison L, Randrianjohany E (1987) Angraecoid orchids and hawk-moths in Central Madagascar specialized pollination systems and generalist foragers. Biotropica 19:310-318. https:// doi.org/10.2307/2388628 
Paulus HF (2005) Pollination biology of central European orchids (Bestäubungsbiologie heimischer Orchideen) Die Orchideen Deutschlands. Arbeitskreise heimische Orchideen, Uhlstädt-Kirchhasel

Pellissier L, Vittoz P, Internicola AI, Gigord LDB (2010) Generalized food-deceptive orchid species flower earlier and occur at lower altitudes than rewarding ones. J Plant Ecol 3:243-250. https://doi.org/ 10.1093/jpe/rtq012

Pérez-Hérnandez H, Damon A, Valle-Mora J, Sánchez-Guillen D (2011) Orchid pollination: specialization in chance? Bot J Linn Soc 165: 251-266. https://doi.org/10.1111/j.1095-8339.2010.01109.x

Peter CI, Johnson SD (2006) Doing the twist: a test of Darwin's crosspollination hypothesis for pollinarium reconfiguration. Biol Lett 2: 65-68. https://doi.org/10.1098/rsbl.2005.0385

Procházka F, Velísek V (1983) Orchideje naši přirody. Československá Academie Věd, Praha

R Core Team (2018) R: A language and environment for statistical computing. R Foundation for Statistical Computing, Vienna, Austria. URL https://www.R-project.org/

Radak BD, Rat MM, Anačkov GT (2012) Morphological variability of populations of Dactylorhiza maculata (L.) Soó and D. majalis (Reichenb.) P.F. Hunt et Summerhayes (Orchidales, Orchidaceae) from Stara Planina Mountain (Serbia). Zb Matice Srpza Prir Nauk 665:33-44. https://doi.org/10.2298/zmspn1222033r

Renner SS (2005) Rewardless flowers in the angiosperms and the role of insect cognition in their evolution. In: Waser NM, Olerton J (eds) Plant-pollinator interactions: from specialization to generalization. The University of Chicago Press, Chicago and London, pp 123-144

Robertson JL, Wyatt R (1990) Evidence for pollination ecotypes in the yellow-fringed orchid, Platanthera ciliaris. Evolution 44:121-133. https://doi.org/10.2307/2409528

Ruiz JL (2010) Polinizadores potenciales y visitantes de Dactylorhiza spp. en los Pirineos (Huesca y Lérida) y el macizo Cazorla-Segura (Jaén, España) (Insecta). Microbotánica Jaén. http://www. micobotanicajaen.com/Revista/Articulos/JLaraR/Polinizadores/ Dactylorhiza.html. Accessed 16 January 2019

Russo L (2016) Positive and negative impacts of non-native bee species around the world. Insects 7:69. https://doi.org/10.3390/ insects7040069

Ruttner F (1988) Biogeography and taxonomy of honey bees. SpringerVerlag. In: Heidelberg. Berlin, New York

Sexton R (2014) The moth pollinators of greater butterfly orchids Platanthera chlorantha in Central Scotland. J Hardy Orchid Soc 11:14-22

Sletvold N, Ågren J (2011) Nonadditive effects of floral display and spur length on reproductive success in a deceptive orchid. Ecology 92: 2167-2174. https://doi.org/10.1890/11-0791.1

Ssymank A, Kearns CA, Pape T, Thompson FC (2008) Pollinating flies (Diptera): a major contribution to plant diversity and agricultural production. Biodiversity 9:86-89. https://doi.org/10.1080/ 14888386.2008.9712892

Stang M, Klinkhamer PGL, van der Meijden E (2006) Size constraints and flower abundance determine the number of interactions in a plant-flower visitor web. Oikos 112:111-121. https://doi.org/10. 1111/j.0030-1299.2006.14199.x

Stang M, Klinkhamer PGL, Waser NM, Stang I, van der Meijden E (2009) Size-specific interaction patterns and size matching in a plant-pollinator interaction web. Ann Bot 103:1459-1469. https:// doi.org/10.1093/aob/mcp027

Steen R, Mundal D (2013) New video registration of Autographa pulchrina (Haworth, 1809) (Lepidoptera, Noctuidae) and Sphinx pinastri L., 1758 (Lepidoptera, Sphingidae) pollinating Platanthera bifolia latiflora (Orchidaceae) in Norway. Norweg J Ento 60:57-61

Sun H-Q, Cheng J, Zhang F-M, Luo Y-B, Ge S (2009) Reproductive success of non-rewarding Cypripedium japonicum benefits from low spatial dispersion pattern and asynchronous flowering. Ann Bot 103:1227-1237. https://doi.org/10.1093/aob/mcp066

Tremblay RL, Ackerman JD, Zimmerman JK, Calvo RN (2005) Variation in sexual reproduction in orchids and its evolutionary consequences: a spasmodic journey to diversification. Biol J Linn Soc 84:1-54. https://doi.org/10.1111/j.1095-8312.2004.00400.x

Trunschke J, Sletvold N, Ågren J (2017) Interaction intensity and pollinator-mediated selection. New Phytol 214:1381-1389. https:// doi.org/10.1111/nph.14479

Vakhrameeva MG, Tatarenko IV, Varlygina TI, Totosyan GK, Zagulski MN (2008) Orchids of Russia and adjacent countries (within the borders of the former USSR). A.R.G. Gantner Verlag K. G., Ruggell

Vallius E, Buchsbaum U, Nazarov V (2013) Pollination activity of Zygaena filipendulae (Linnaeus, 1758) (Lepidoptera: Zygaenidae) in Anacamptis pyramidalis orchid on the north Bull Island (Ireland). Entomofauna 34:357-368

Vöth W (1993) Dactylorhiza lapponica (HARTM.) SOÓ (Orchidaceae) in Niederösterreich. Verh Zool-Bot Ges Österr 130:95-98

Vöth W (1999) Lebensgeschichte und Bestäuber der Orchideen am Beispiel von Niederösterreich. Stapfia 65:1-257

Wang Y, Ma L, Zhang W, Cui X, Wang H, Xu B (2016) Comparison of the nutrient composition of royal jelly and worker jelly of honey bees (Apis mellifera). Apidologie 47:48-56. https://doi.org/10. 1007/s13592-015-0374-x

Waser NM, Ollerton J (2006) Plant-pollinator interactions: from specialization to generalization. The University of Chicago Press, Chicago

Willmer P (2011) Pollination and floral ecology. Princeton University Press, Princeton

Wróblewska A, Szczepaniak L, Bajguz A, Jedrzejczyk I, Tałałaj I, Ostrowiecka B, Brzosko E, Jermakowicz E, Mirski P (2019) Deceptive strategy in Dactylorhiza orchids: multidirectional evolution of floral chemistry. Ann Bot. https://doi.org/10.1093/aob/mcz003

Yi Z, Jinchao F, Dayuan X, Weiguo S, Axmacher JC (2012) A comparison of terrestrial arthropod sampling methods. J Resour Ecol 3: 174-182. https://doi.org/10.5814/j.issn.1674-764x.2012.02.010

Zahn A, Englmaier I, Drobny M (2010) Food availability for insectivores in grasslands - arthropod abundance in pastures, meadows and fallow land. Appl Ecol Env Res 8:87-100. https://doi.org/10.15666/aeer/0802_ 087100

Publisher's note Springer Nature remains neutral with regard to jurisdictional claims in published maps and institutional affiliations. 